\title{
A Lattice Dynamical Approach for Finding the Lithium Superionic Conductor Li3Erl6
}

Roman Schlem, Tim Bernges, Cheng Li, Marvin Kraft, Nicolo Minafra, Wolfgang Zeier

Submitted date: 16/01/2020 - Posted date: 20/01/2020

Licence: CC BY-NC-ND 4.0

Citation information: Schlem, Roman; Bernges, Tim; Li, Cheng; Kraft, Marvin; Minafra, Nicolo; Zeier, Wolfgang (2020): A Lattice Dynamical Approach for Finding the Lithium Superionic Conductor Li3Erl6. ChemRxiv. Preprint. https://doi.org/10.26434/chemrxiv.11627451.v1

Driven by the increasing attention that the superionic conductors $\mathrm{Li}_{3} \mathrm{MX}_{6}(\mathrm{M}=\mathrm{Y}, \mathrm{Er}$, In, $\mathrm{La} ; \mathrm{X}=\mathrm{Cl}, \mathrm{Br}, \mathrm{I})$ have gained recently for the use of solid-state batteries, and the idea that a softer, more polarizable anion sublattice is beneficial for ionic transport, here we report $\mathrm{Li}_{3} \mathrm{Erl}_{6}$, the first experimentally-obtained iodine-based compound within this material system of ionic conductors. Using a combination of synchrotron and neutron diffraction, we elucidate the structure, the lithium positions and possible diffusion pathways of $\mathrm{Li}_{3} \mathrm{Erl}_{6}$. Temperature-dependent impedance spectroscopy shows low activation energies of 0.37 and $0.38 \mathrm{eV}$ alongside promising ionic conductivities of $0.65 \mathrm{mS} \cdot \mathrm{cm}^{-1}$ and $0.39 \mathrm{mS} \cdot \mathrm{cm}^{-1}$ directly after ball milling and the subsequently annealed $\mathrm{Li}_{3} \mathrm{Erl}_{6}$, respectively. Speed of sound measurements are used to determine the Debye frequency of the lattice as a descriptor of the lattice dynamics and overall lattice softness, and $\mathrm{Li}_{3} \mathrm{Erl}_{6}$ is compared to the known material $\mathrm{Li}_{3} \mathrm{ErCl}_{6}$. The softer, more polarizable framework from the iodide anion leads to improved ionic transport, showing that the idea of softer lattices holds up in this class of materials. This work provides $\mathrm{Li}_{3} \mathrm{Erl}_{6}$ as an interesting novel framework for optimization in the class of halide-based ionic conductors.

File list (2)

manuscript.pdf (1.85 MiB)

view on ChemRxiv • download file

Supporting Information.pdf (524.31 KiB)

view on ChemRxiv - download file 


\title{
A lattice dynamical approach for finding the lithium superionic conductor $\mathrm{Li}_{3} \mathrm{ErI}_{6}$
}

\author{
Roman Schlem ${ }^{\mathrm{a}, \mathrm{b}}$, Tim Bernges ${ }^{\mathrm{a}, \mathrm{b}}$, Cheng Li ${ }^{\mathrm{c}}$, Marvin A. Kraft ${ }^{\mathrm{a}, \mathrm{b}}$, Nicolo Minafra ${ }^{\mathrm{a}, \mathrm{b}}$, \\ Dr. Wolfgang G. Zeier*a,b \\ anstitute of Physical Chemistry, Justus-Liebig-University Giessen, Heinrich-Buff- \\ Ring 17, D-35392 Giessen, Germany. \\ ${ }^{b}$ Center for Materials Research (LaMa), Justus-Liebig-University Giessen, \\ Heinrich-Buff-Ring 16, D-35392 Giessen, Germany.
}

'Jülich Centre for Neutron Science (JCNS), Forschungszentrum Jülich GmbH, Outstation at SNS, 1 Bethel Valley Road, Oak Ridge, Tennessee 37831-6473,

United States

Driven by the increasing attention that the superionic conductors $\mathrm{Li}_{3} \mathrm{MX}_{6}(\mathrm{M}=\mathrm{Y}, \mathrm{Er}, \mathrm{In}, \mathrm{La}$; $\mathrm{X}=\mathrm{Cl}, \mathrm{Br}, \mathrm{I}$ ) have gained recently for the use of solid-state batteries, and the idea that a softer, more polarizable anion sublattice is beneficial for ionic transport, here we report $\mathrm{Li}_{3} \mathrm{ErI}_{6}$, the first experimentally-obtained iodine-based compound within this material system of ionic conductors. Using a combination of synchrotron and neutron diffraction, we elucidate the structure, the lithium positions and possible diffusion pathways of $\mathrm{Li}_{3} \mathrm{ErI}_{6}$. Temperaturedependent impedance spectroscopy shows low activation energies of 0.37 and $0.38 \mathrm{eV}$ alongside promising ionic conductivities of $0.65 \mathrm{mS} \cdot \mathrm{cm}^{-1}$ and $0.39 \mathrm{mS} \cdot \mathrm{cm}^{-1}$ directly after ball milling and the subsequently annealed $\mathrm{Li}_{3} \mathrm{ErI}_{6}$, respectively. Speed of sound measurements are used to determine the Debye frequency of the lattice as a descriptor of the lattice dynamics and overall lattice softness, and $\mathrm{Li}_{3} \mathrm{ErI}_{6}$ is compared to the known material $\mathrm{Li}_{3} \mathrm{ErCl}_{6}$. The softer, more polarizable framework from the iodide anion leads to improved ionic transport, showing that the idea of softer lattices holds up in this class of materials. This work provides $\mathrm{Li}_{3} \mathrm{ErI}_{6}$ as an interesting novel framework for optimization in the class of halide-based ionic conductors.

\section{Table of contents}

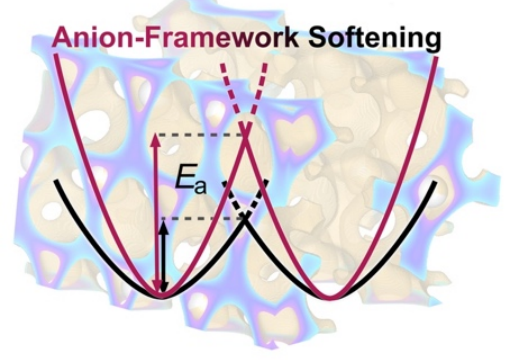


Driven by the rapidly increasing interest in energy storage, the field of all solid-state batteries has garnered significant attention in recent years. ${ }^{1,2}$ Current battery designs mainly involve the usage of liquid organic electrolytes responsible for the ion flow between the electrodes. However, the high flammability of the employed electrolyte leads to safety concerns that could be overcome with a solid-state battery design. ${ }^{3}$ Although remarkable developments have been made in regards to all-solid-state batteries, including the discovery of superionic conductors, the material processing and different electrode and cell designs, the electrochemical and chemical stability of the solid electrolytes remain an issue. ${ }^{4}$

A multitude of different possible electrolytes have been investigated to date and are prominently represented for instance the garnets $\mathrm{Li}_{7} \mathrm{La}_{3} \mathrm{Zr}_{2} \mathrm{O}_{12}{ }^{5-8}$ However, the oxides exhibit a significantly lower ionic conductivity compared to thiophosphate-based electrolytes such as $\mathrm{Li}_{10} \mathrm{GeP}_{2} \mathrm{~S}_{12}{ }^{9-11}$ or the halide argyrodites $\mathrm{Li}_{6} \mathrm{PS}_{5} \mathrm{X}^{12-15}(\mathrm{X}=\mathrm{Cl}, \mathrm{Br}$ and $\mathrm{I})$, all of which are faster ionic conductors stemming from the polarizable sulfide environment. ${ }^{4}$ Although being known for decades, ${ }^{16}$ the rare-earth halides $\mathrm{Li}_{3} \mathrm{MX}_{6}$ have only recently attracted rising interest with multiple compounds within this family $\left(\mathrm{Li}_{3} \mathrm{YBr}_{6},{ }^{17} \mathrm{Li}_{3} \mathrm{InCl}_{6}{ }^{18}, \mathrm{Li}_{2.7} \mathrm{Er}_{0.7} \mathrm{Zr}_{0.3} \mathrm{Cl}_{6}{ }^{19}\right)$ showing an experimental ionic conductivity in the $1 \mathrm{mS} \cdot \mathrm{cm}^{-1}$ range, with further compounds having been predicted to perform accordingly. ${ }^{20}$ In addition to having an inherently high ionic conductivity, these halide based compounds are expected to exhibit a desired oxidation stability higher than the thiophosphate based compounds and in the case of $\mathrm{Li}_{3} \mathrm{InCl}_{6}$ can even be simply prepared in water as well as fully dried and recovered after exposition to (humid) air. ${ }^{17,18}$ These advantages enable upscaling capabilities, which makes them particular interesting for industrial use. While multiple compounds have been successfully synthesized, ${ }^{16-18,21,22}$ all these materials generally lack a full structural description and the correlation between the structural features and the underlying ionic transport behavior remains mostly elusive. ${ }^{23}$ Further, so far, very limited substitution studies on those materials can be found, ${ }^{19,24}$ thereby leaving a multitude of opportunities to further enhance the electrochemical performance of this material class, as previously done for different lithium ion conductors. ${ }^{14,25}$

Recently, the widening of diffusion pathways and the idea that a softer, more polarizable lattice will lead to better ionic transport has been used to explore novel compounds theoretically and experimentally. ${ }^{20,21,26}$ Especially within the field of lithium and sodium thiophosphates the softer lattice, which can be expressed via the phonon band center or its Debye frequency, ${ }^{15,27-}$ ${ }^{30}$ leads to beneficially lower activation barriers for ionic transport. Recently, this idea has been extended to theoretically screen for novel ionic conductors using certain design principles such 
as oxidative stability and lattice polarizability, ${ }^{21}$ which has led to the finding and resurgence of $\mathrm{Li}_{3} \mathrm{ErCl}_{6}$ among the lithium conducting rare-earth halides.

Driven by the idea that a more polarizable anion will be needed in the rare-earth $\mathrm{Li}_{3} \mathrm{MX}_{6}$ family, along with the fact that no iodine-based compound within the rare-earth $\mathrm{Li}_{3} \mathrm{MI}_{6}$ family has been experimentally reported, here, we show the successful synthesis of $\mathrm{Li}_{3} \mathrm{ErI}_{6}$. A combination of synchrotron X-ray diffraction and neutron diffraction finds the same crystal structure previously predicted for the isostructural $\mathrm{Li}_{3} \mathrm{YI}_{6}$. With the space group of $C 2 / c$ this compound resembles a new structure type within the $\mathrm{Li}_{3} \mathrm{MX}_{6}$ material system. Using bond valence sum analysis and impedance spectroscopy, a likely in-plane diffusion and corresponding high ionic conductivities close to the $1 \mathrm{mS} \cdot \mathrm{cm}^{-1}$ range and activation barriers of $0.37-0.38 \mathrm{eV}$ are reported. Furthermore, using experimentally determined Debye frequencies, the lattice softness of this novel $\mathrm{Li}_{3} \mathrm{ErI}_{6}$ is compared to the known $\mathrm{Li}_{3} \mathrm{ErCl}_{6}$, showing that indeed a softer lattice has been achieved that in turn leads to improved ionic transport. Overall, this work reports $\mathrm{Li}_{3} \mathrm{ErI}_{6}$ as a promising new solid electrolyte within the rare-earth halide family and the concept of using lattice dynamics for optimizing ionic transport is experimentally transferred from the thiophosphates to this class of materials for the first time.

Structure of $\mathrm{Li}_{3} E r I_{6}$. In this work, $\mathrm{Li}_{3} \mathrm{ErI}_{6}$ was prepared for the first time using a mechanochemical alloying (ball-milling) approach with a subsequent crystallization step. A comparison of the collected laboratory X-ray diffraction data of the two $\mathrm{Li}_{3} \mathrm{ErI}_{6}$ sample preparation routes, i.e. the as prepared after milling and after subsequent crystallization, can be found in the Supporting Information (Figure S1). While the main reflections of $\mathrm{Li}_{3} \mathrm{ErI}_{6}$ can be found already after milling, low intensities and a significant peak broadening suggest an occurring amorphization during the milling procedure and has been previously shown for other compounds within the $\mathrm{Li}_{3} \mathrm{MX}_{6}$ material-class. ${ }^{23}$ In order to solve the structure of $\mathrm{Li}_{3} \mathrm{ErI}_{6}$, a combination of room temperature synchrotron and neutron diffraction is employed. Here, we use the high-resolution synchrotron diffraction data to accurately identify the framework of the structure, while the neutron diffraction is used to provide insight into the lithium positions and corresponding diffusion pathways. Both diffraction techniques were carried out on the $5 \mathrm{~min}$ crystallized samples, due to their higher crystallinity compared to the ball milled (as prepared) sample.

Recently, the space groups $C 2 / c$ and $C 2$ were theoretically proposed for $\mathrm{Li}_{3} \mathrm{YI}_{6}{ }^{20}$ In addition, here, $C 2 / m$ was tested as a possible space group because $\mathrm{Li}_{3} \mathrm{YBr}_{6}$ is known to crystallize in a crystal structure corresponding to this space group. Here Pawley fits (see Supporting 
Information Figure S2) are carried out to obtain information about the lattice and overall symmetry. The resulting fit values as well as a visual assessment of the profile differences are used to compare the observed reflections to the theoretically possible reflections corresponding to the different tested structural models. A full match of all observed and possible reflection positions is only obtained by using the space groups $C 2$ and $\mathrm{C} 2 / \mathrm{c}$. Both space groups are very similar and exhibit the same polyhedral connectivity, therefore, $C 2 / \mathrm{c}$ with a higher symmetry is chosen for the following refinements. Figure 1 shows the Rietveld refinement results against the collected synchrotron diffraction data (a) and neutron diffraction data (b).
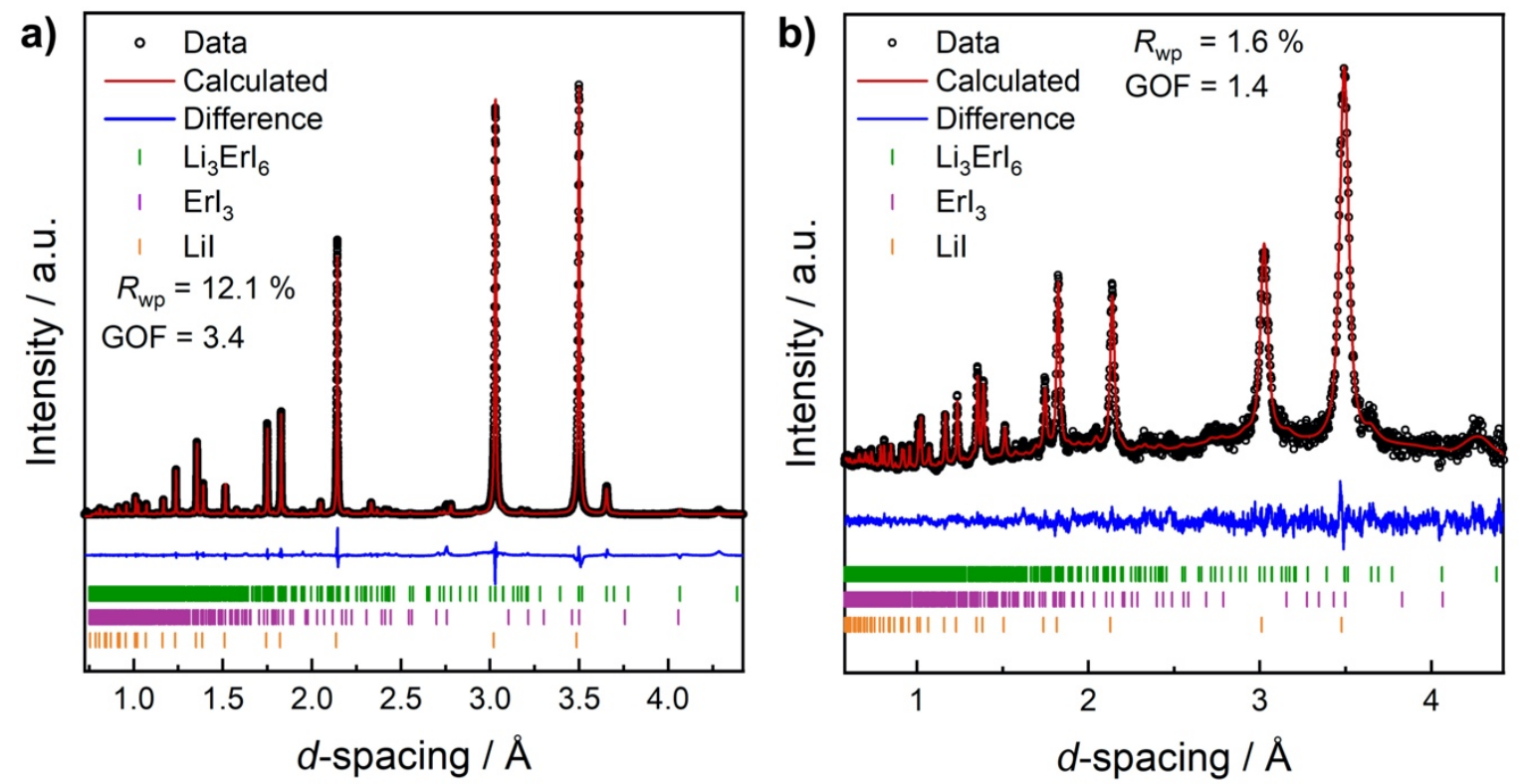

Figure 1: Rietveld refinements against collected synchrotron diffraction data (a) and neutron diffraction data (b) using a structure corresponding to the C2/c space group. Minor amounts of impurities of LiI and ErI3 was found with total amounts of 4 wt\% (a) and 5 wt\% (b), respectively.

The best possible fit of the synchrotron diffraction pattern was achieved using the monoclinic $C 2 / c$ space group, which corresponds to the highest symmetry space group of $\mathrm{Li}_{3} \mathrm{YI}_{6}$ proposed by $\mathrm{Xu}$ et al..$^{20}$ Due to the similar ionic radii ${ }^{31}$ of $\mathrm{Y}(90 \mathrm{pm})$ and $\mathrm{Er}(89 \mathrm{pm})$ as well as the fact that the corresponding chlorides $\left(\mathrm{Li}_{3} \mathrm{YCl}_{6}\right.$ and $\left.\mathrm{Li}_{3} \mathrm{ErCl}_{6}\right)$ are isostructural, ${ }^{17,21}$ it is not surprising to find the same space group for $\mathrm{Li}_{3} \mathrm{ErI}_{6}$. A comparison of the crystal structure framework, obtained from the synchrotron diffraction experiment and the full structure including the lithium positions, obtained from the neutron diffraction experiment is displayed in Figure 2. 


\section{OLithium (4d, 8f, 4e) $\odot$ Erbium (4d, 8f) Olodine (8f)}

\section{Synchrotron diffraction \\ (Framework)}

a)

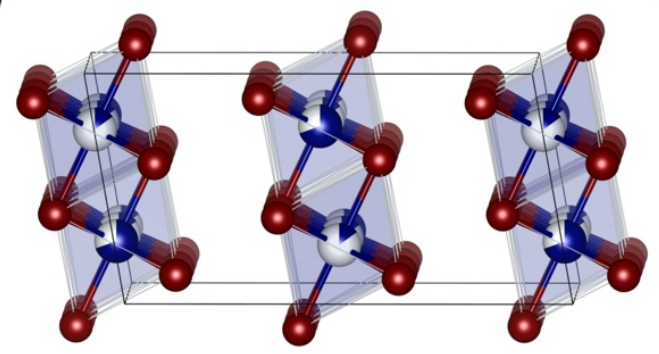

b)

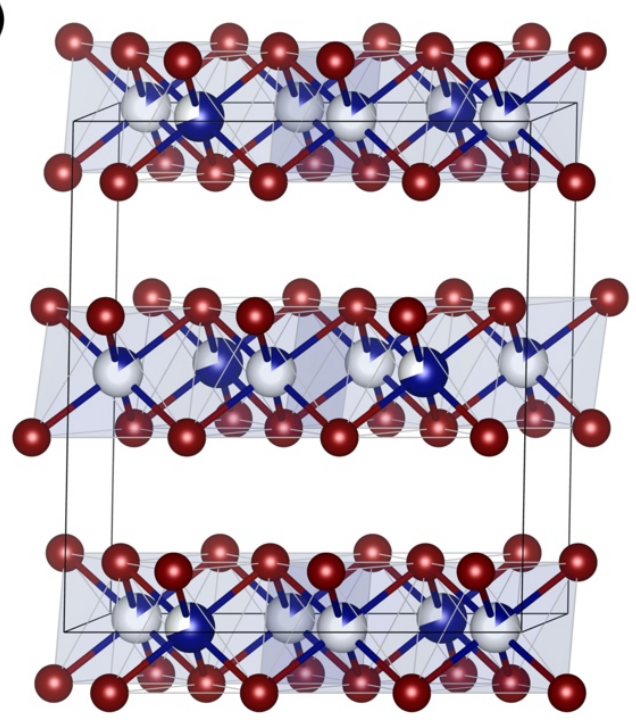

Neutron diffraction

(Full structure)

c)

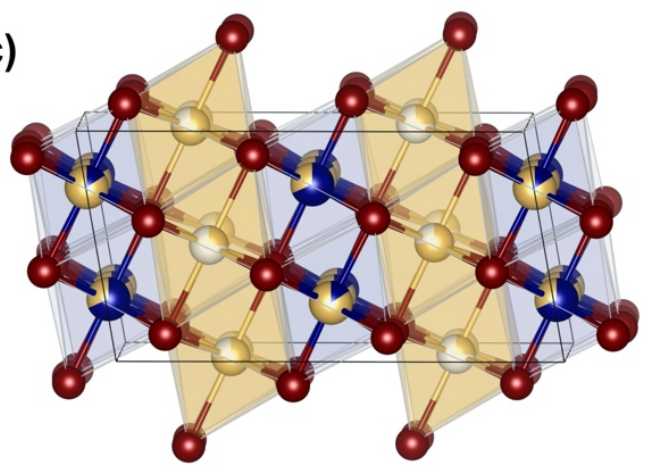

d)

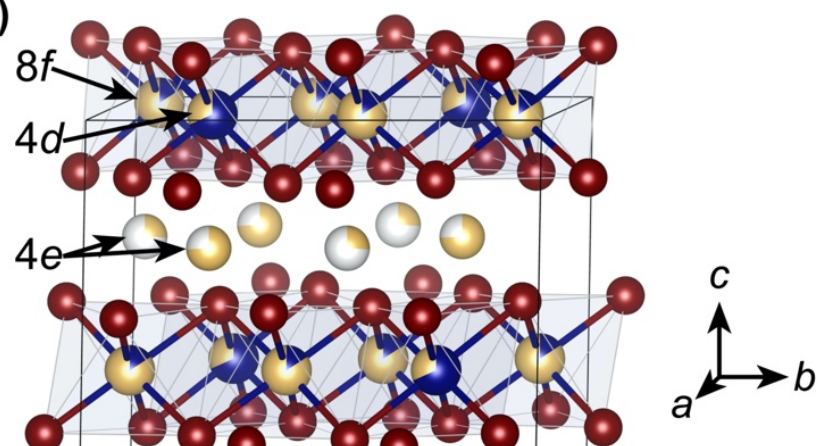

Figure 2: Comparison of the structural framework and the full structure of Li $i_{3} E r I_{6}$. Layers of partially occupied, edge sharing ErI $\sigma_{6}^{3-}$ octahedra can be found in the ab-plane ( $\left.a, b\right)$. Additionally, lithium can be found on those partially vacant sites resulting in a cationexchange-defect (c). The, from the framework resulting vacant layers are being occupied by edge sharing LiI $I_{6}^{5-}$ octahedra, ultimately resulting in alternating layers of $\left(\operatorname{Er}_{x} \operatorname{Li}_{(1-x)}\right) I_{6}{ }^{(5-2 x)-}$ and LiI $I_{6}^{5-}$ octahedra.

The structural framework can be described as isolated layers of edge-sharing $\operatorname{ErI}_{6}{ }^{3-}$ octahedra in the $a b$-plane, in which erbium partially occupies two different Wyckoff positions ( $4 d$ and $8 f$ ). Multiple different possible disorder-positions were tested for erbium, because the chlorine and bromine-based compounds in the $\mathrm{Li}_{3} \mathrm{MX}_{6}$ family have shown a significant rare-earth disorder, ${ }^{17,21}$ which has shown to dramatically affect the ionic transport. ${ }^{23}$ An additional stable Er position (8f), together with the expected $4 d$ site, was found to correspond to one of the theoretical proposed lithium positions in $\mathrm{Li}_{3} \mathrm{LaI}_{6}{ }^{20}$ In other words, the lithium ions in the 
structure reside on both of those partially vacant positions, leading to the existence of $\mathrm{a}^{+}$$\mathrm{Er}^{3+}$ disorder within the layers. Furthermore, two more lithium positions can be found using neutron diffraction in the interlayers between the edge-sharing $\operatorname{ErI}_{6}{ }^{3-}$ octahedra, corresponding to an additional layer of edge-sharing $\mathrm{LiI}_{6}{ }^{5-}$ octahedra. In essence, the structure can be regarded as alternating layers of edge sharing $\left(\operatorname{Er}_{\mathrm{x}} \mathrm{Li}_{(1-\mathrm{x})}\right) \mathrm{I}_{6}{ }^{(5-2 \mathrm{x})-}$ and $\mathrm{LiI}_{6}{ }^{5-}$ octahedra. These edge-sharing octahedra result in tetrahedral voids, likely representing transitional positions for the lithium diffusion as it has been previously discussed for similar materials within the $\mathrm{Li}_{3} \mathrm{MX}_{6}$ material system. ${ }^{32}$ Overall, the disorder of $\mathrm{Li}^{+}$within the $\mathrm{Li}^{+}$- layer in the $a b$-plane and the $\mathrm{Li}^{+}$in the ErI $_{6}{ }^{3-}$ plane, suggests a possible three-dimensional diffusion. ${ }^{33}$
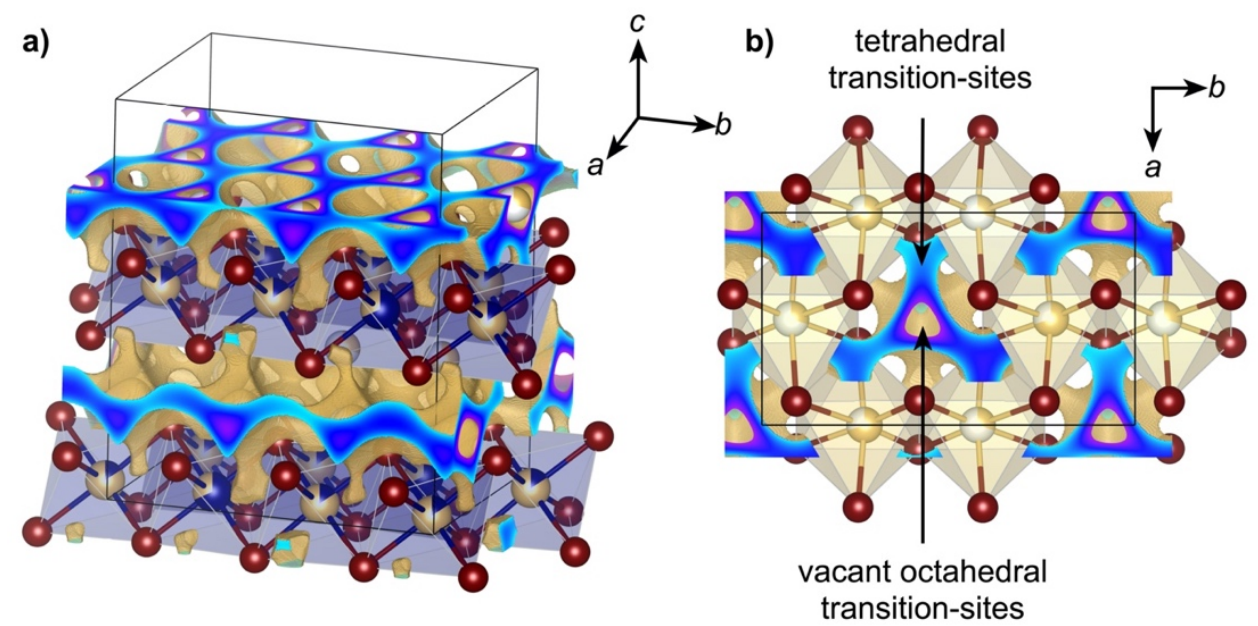

Figure 3: Possible lithium diffusion pathways obtained by a bond valence sum calculation. The blue sections (a) show the strongly interconnected lithium sites in the a-b plane possibly leading to a fast in-plane diffusion. (b) The edge sharing LiI ${ }_{6}{ }^{-}$octahedra form tetrahedral voids that may act as a transitional state.

In order to estimate the possible lithium diffusion pathways, bond valence sum maps are calculated for $\mathrm{Li}_{3} \mathrm{ErI}_{6}$. The result is shown in Figure 3 in which the beige isosurface corresponds to an electrostatic estimation of the probable lithium residence and lithium diffusion pathway. The sections, shown in blue in Figure 3a represent slices through the structure and show the strongly interconnected nature of the lithium positions in the $a b$-plane. However, no apparent diffusion appears to occur in the $c$-direction. While it is possible that the diffusion mechanism in $\mathrm{Li}_{3} \mathrm{ErI}_{6}$ is mainly two dimensional, a possible diffusion in $c$-direction cannot be ruled out considering that BVS analyses are challenging for disordered materials, ${ }^{34}$ highlighting the need for a more detailed theoretical analysis. Indeed, the strong disorder between $\mathrm{Li}^{+}$and $\mathrm{Er}^{3+}$ of around $33 \%$ indicates occurring diffusion along the c-axis. Figure $3 \mathrm{~b}$ shows a view of the lithium-only $a b$-plane. The edge sharing nature of the octahedra leaves tetrahedral voids that may act as transitional states for lithium diffusion with an additional vacant octahedral site 
centered between six partially occupied $\mathrm{LiI}_{6}{ }^{5-}$ octahedra, further corroborating the diffusion pathways in the $a b$-plane.

Ionic transport properties. In order to probe the ionic transport properties, temperaturedependent impedance spectroscopy measurements are performed. Figure 4a shows the comparison of representative Nyquist plots for the ball milled (as prepared) and the $5 \mathrm{~min}$ subsequently annealed sample that was used for the structural study above. In addition, the Arrhenius plots (Figure 4b), the extracted activation barriers, and the room-temperature ionic conductivities are given. It is possible to fit the impedance data using only one parallel constant phase element (CPE) and resistor, in series to another CPE, however, the resulting low $\alpha$-values of around 0.75 indicate a more complex underlying process. ${ }^{35}$ More reasonably, a second contribution was assigned to a possible grain boundary ( $\mathrm{gb}$ ) contribution for the ball milled (as prepared) sample and an electrode-related (er) interface contribution for the annealed sample. The assignment of $(\mathrm{gb})$ or (er) contribution was performed using the respective capacitances for each process. Here, for the ball milled (as prepared) sample the two contributions show capacitances of $94 \cdot \mathrm{cm}^{-2} \mathrm{pF}$ (bulk) and $0.13 \mathrm{nF} \cdot \mathrm{cm}^{-2}(\mathrm{gb})$, while the ball milled sample with an additional 5 min annealing step shows capacitances of $51 \mathrm{pF} \cdot \mathrm{cm}^{-2}$ (bulk) and $0.95 \mu \mathrm{F} \cdot \mathrm{cm}^{-2}$ (er), further suggesting an underlying electrolyte-electrode interface contribution. ${ }^{36}$ This different behavior is likely related to a subtle change in the microstructure, as the grain-size and contact with the crystallization and with it the mechanical properties and interface properties at the electrodes. Assigning more than one process to the Nyquist plot, leads to an improvement of the $\alpha$-value from 0.75 to up to 0.89 for the bulk process of the ball milled (as prepared) sample. Nevertheless, all of those contributions cannot be fully deconvoluted and therefore, all reported conductivities reflect the total conductivity of the material.

An activation energy of around $0.37 / 0.38 \mathrm{eV}$ can be found for both samples, in good agreement with the predicted values for this structure type. ${ }^{20}$ An ionic conductivity of around $0.65(7) \mathrm{mS} \cdot \mathrm{cm}^{-1}$ and $0.39(6) \mathrm{mS} \cdot \mathrm{cm}^{-1}$ for the ball milled (as prepared) sample and the ball milled sample with a subsequent crystallization step of 5 min respectively can be found. ${ }^{20}$ The higher conductivity of the ball milled (as prepared) sample is in good agreement with previously observed trends for other materials within the $\mathrm{Li}_{3} \mathrm{MX}_{6}$ system in which local distortions and different degrees of the disorders exist, ${ }^{17,18,21,23}$ further corroborating that directly after mechanochemical synthesis of $\mathrm{Li}_{3} \mathrm{MX}_{6}$ higher ionic conductivities can be obtained. ${ }^{23}$ 

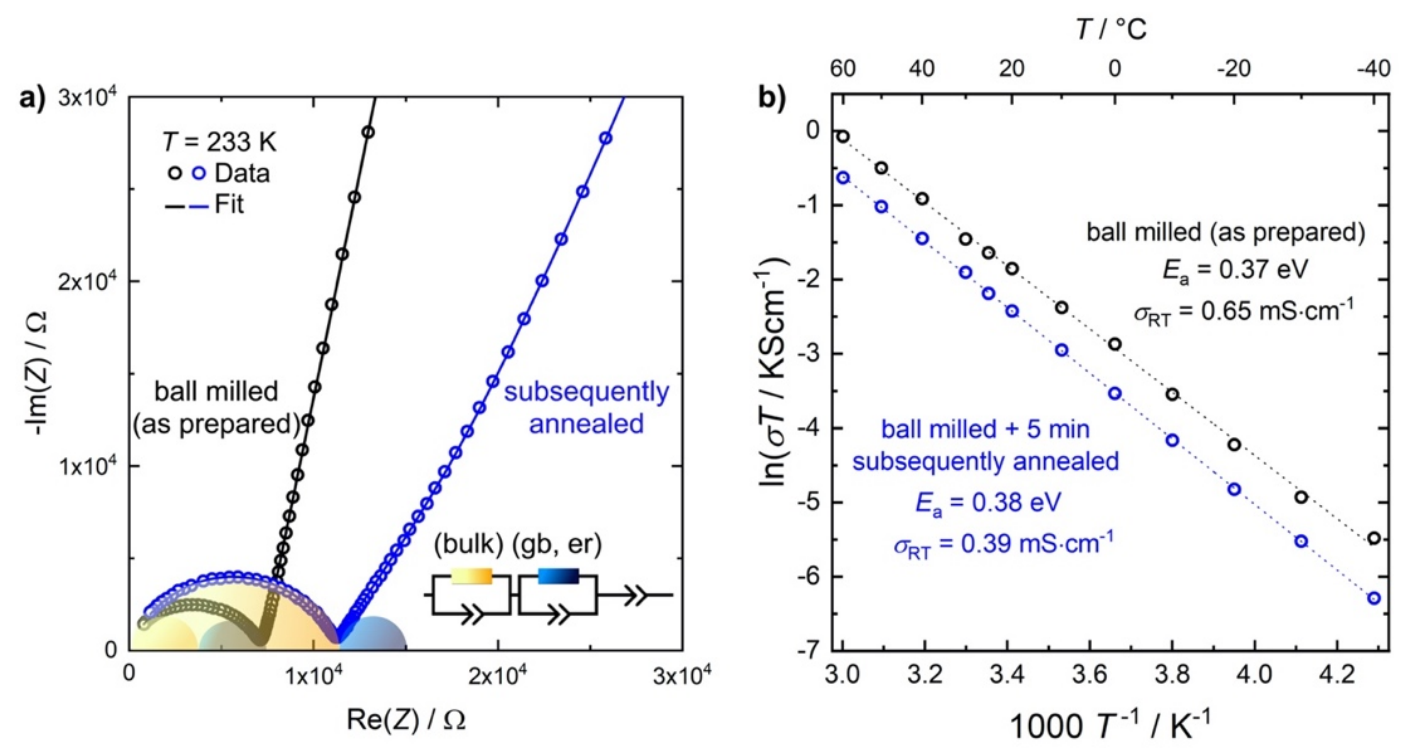

Figure 4: Representative Nyquist-plots for the two differently prepared samples (a) and calculated Arrhenius-plots (b) of the total ionic conductivity and its corresponding activation energies. The impedance data was fitted with two parallel CPE-resistor-elements and another CPE element in series, corresponding to different underlying process (bulk, grain-boundary ( $g b)$ and electrode related (er)).

Lattice dynamics and ionic transport correlation. Recent studies have shown the influence of the lattice dynamics on the ionic transport, in which softer lattices with more polarizable anions are greatly beneficial for the ionic transport. ${ }^{15,21,27-30}$ The softness of a lattice or material itself is often measured via the phonon band center or its Debye frequency. ${ }^{15,27-30}$ With the incorporation of a larger, more polarizable anion, the lattice softens and the enthalpy and entropy of migration decrease. As both the enthalpy and entropy are convoluted in the activation barrier and Arrhenius pre-factor of the ionic conductivity, ${ }^{4}$ the ionic conductivity is severely affected by softer, more polarizable anion lattices. ${ }^{29}$

In this work, $\mathrm{Li}_{3} \mathrm{ErI}_{6}$ was synthesized based on the hypothesis that the larger and more polarizable iodide would lead to beneficial ionic transport when compared to the known $\mathrm{Li}_{3} \mathrm{ErCl}_{6}$. In order to explore this idea, speed of sound measurements were performed to obtain the Debye frequency of the lattice of both $\mathrm{Li}_{3} \mathrm{ErCl}_{6}$ and $\mathrm{Li}_{3} \mathrm{ErI}_{6}$. For a fair comparison, $\mathrm{Li}_{3} \mathrm{ErCl}_{6}$ was used with similar milling and crystallization times to ensure a comparable crystallinity, and the synthesis and ionic conductivities are reported elsewhere. ${ }^{23}$ The longitudinal, transverse and mean speeds of sound of both $\mathrm{Li}_{3} \mathrm{ErCl}_{6}$ and $\mathrm{Li}_{3} \mathrm{ErI}_{6}$ can be found in Figure 5a. Moving from the chloride anion to the iodide anion, the speed of sound and with it the calculated Debye frequencies (see Figure 5b) decrease (see Eq. 1 and 2, Experimental Section). As these parameters reflect the average bond strength, independent of the structure type, the iodide anion 
indeed leads to an overall softer anionic framework in $\mathrm{Li}_{3} \mathrm{ErI}_{6}$, compared to $\mathrm{Li}_{3} \mathrm{ErCl}_{6}$. When comparing two different structure types, it is worth mentioning that static effects such as the average jump distance and polyhedral connectivity can influence the transport properties. However, both structures of $\mathrm{Li}_{3} \mathrm{ErI}_{6}$ and $\mathrm{Li}_{3} \mathrm{ErCl}_{6}$ exhibit the same polyhedral connectivity with transport mediated by a transition across a vacant tetrahedral site.

The activation barriers $E_{\mathrm{a}}$ for ionic motion, the Arrhenius pre-factor $\sigma_{0}$ (obtained by the temperature-dependence of the ionic conductivity) and the room-temperature conductivity of $\mathrm{Li}_{3} \mathrm{ErCl}_{6}$ and $\mathrm{Li}_{3} \mathrm{ErI}_{6}$ are shown as a function of the Debye frequency (see Figure $5 \mathrm{c}$ ). When using the Debye frequency as a descriptor of the lattice dynamics of ionic conductors, as recently shown for thiophosphate-based ionic conductors, ${ }^{29}$ the softer lattice within the iodide compound leads to a lower activation barrier, reduced pre-factor of ionic motion and an overall improved ionic conductivity (Figure 5c and schematically shown in Figure 5d). It seems that this class of lithium rare-earth halides appears to further support that softer lattices can be beneficial for ionic transport and thereby leaving possibilities to further enhance the ionic transport properties. 
a)

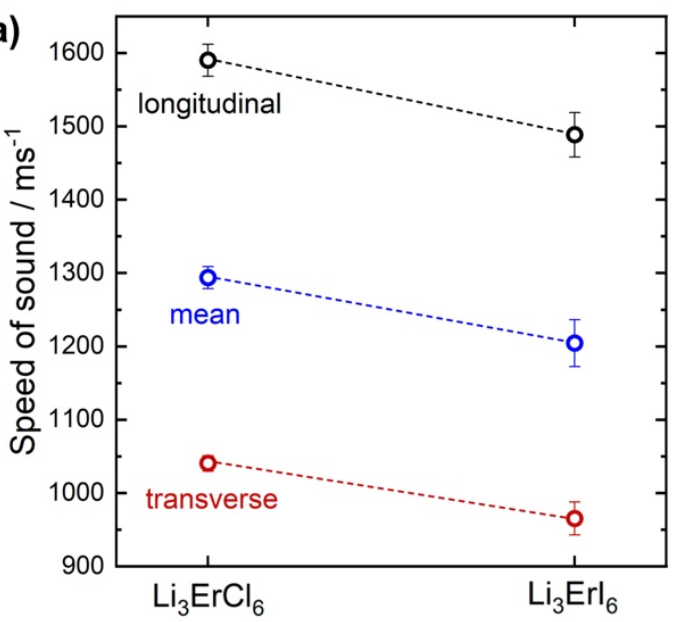

c)

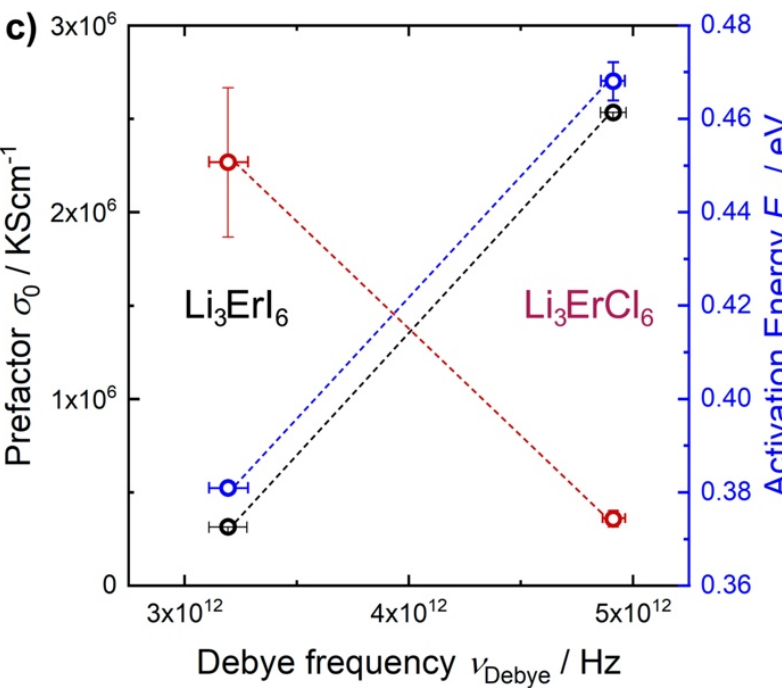

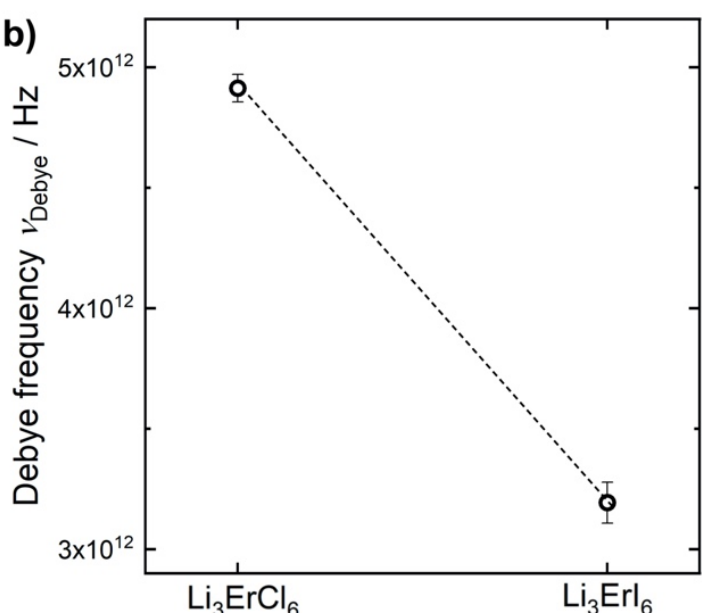

d)

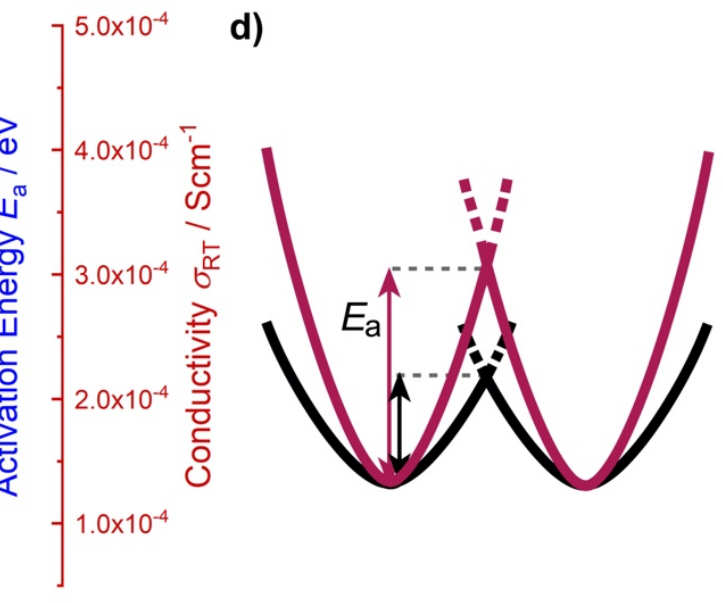

Figure 5: a) Speeds of sound of $\mathrm{Li}_{3} \mathrm{ErCl}_{6}$ and $\mathrm{Li}_{3} \mathrm{ErI}_{6}$ and b) the corresponding Debye frequencies, showing a softer lattice for $\mathrm{Li}_{3} \mathrm{ErI}_{6 .}$. c) Arrhenius pre-factor $\sigma_{0}$, activation barrier $E_{A}$, room temperature conductivity $\sigma$ versus the Debye frequencies. d) Schematic of how a softer anionic sublattice in $\mathrm{Li}_{3} \mathrm{ErI}_{6}$ compared to $\mathrm{Li}_{3} \mathrm{ErCl} \mathrm{C}_{6}$ leads to larger vibrational amplitudes and lower activation barriers. $\mathrm{Li}_{3} \mathrm{ErCl}_{6}$ data are taken from ref 22.

In conclusion, we report the successful synthesis of the novel lithium ion conductor $\mathrm{Li}_{3} \mathrm{ErI}_{6}$. The structure solution was carried out using Rietveld-refinements against a combination of synchrotron- and neutron diffraction datasets and yields a monoclinic crystal structure with the $C 2 / \mathrm{c}$ space group. A bond valance sum analysis shows the strongly interconnected nature of the lithium positions in the $a$ - $b$-plane likely resulting in a high diffusivity and ionic conductivity. An activation barrier of 0.37 and $0.38 \mathrm{eV}$ was obtained that is governed by the good ionic conductivity of $0.65(7) \mathrm{mS} \cdot \mathrm{cm}^{-1}$ and $0.39(6) \mathrm{mS} \cdot \mathrm{cm}^{-1}$ for the ball milled $\mathrm{Li}_{3} \mathrm{ErI}_{6}$ and the subsequently annealed $\mathrm{Li}_{3} \mathrm{ErI}_{6}$ samples, respectively. 
Guided by the idea that the iodide anion leads to improved ionic transport as it constitutes a more polarizable lattice framework, the lattice dynamics of $\mathrm{Li}_{3} \mathrm{ErI}_{6}$ are measured and compared to $\mathrm{Li}_{3} \mathrm{ErCl}_{6}$. The softer lattice leads to a decreased activation barrier and improved ionic conductivity, showing that even within this class of lithium rare-earth halides the lattice dynamics severely affect the ionic motion.

$\mathrm{Li}_{3} \mathrm{ErI}_{6}$ represents a novel material in the lithium - rare earth - halide family of ionic conductors and opens new possibilities for better understanding the structure-transport properties in this class of superionic solid-state electrolytes.

\section{EXPERIMENTAL METHODS}

Synthesis. The preparations of $\mathrm{Li}_{3} \mathrm{ErI}_{6}$ were carried out under argon atmosphere. Stoichiometric amounts of $\mathrm{ErI}_{3}$ (Alfa Aesar, $99.9 \%$ ) and LiI (Alfa Aesar, $99.95 \%$ ) were used for the synthesis. While $\mathrm{ErI}_{3}$ was used as received, LiI was dried for at least $48 \mathrm{~h}$ at $450{ }^{\circ} \mathrm{C}$ under dynamic vacuum to ensure the removal of the existing $\mathrm{LiI}\left(\mathrm{H}_{2} \mathrm{O}\right)$ impurity phase ${ }^{30}$ For the mechanochemical synthesis, the chemicals were placed in a $\mathrm{ZrO}_{2}$ ball milling cup with $3 \mathrm{~mm} \mathrm{ZrO}_{2}$ milling media with a $30: 1$ mass ratio of milling media to precursor powder. The milling was performed in a planetary ball mill at $500 \mathrm{rpm}$ for a total of 250 cycles, in which one cycle consists of $10 \mathrm{~min}$ milling followed by $10 \mathrm{~min}$ rest. To increase the crystallinity of the samples, the obtained powder was hand pressed and loaded into quartz ampoules and annealed for 5 minutes at $550{ }^{\circ} \mathrm{C}$ under vacuum. Before using, all ampoules ( $\sim 10 \mathrm{~cm}$ long, $10 \mathrm{~mm}$ inner diameter) were heated at $800{ }^{\circ} \mathrm{C}$ for at least 1.5 hours under dynamic vacuum to ensure the removal of all traces of water. To ensure precise annealing times, the sealed ampoules were placed into the hot furnace and air quenched afterwards. The transport properties were collected on the same sample set that was measured by synchrotron diffraction. For the neutron data collection, two further syntheses were prepared and afterwards mixed in order to obtain sufficient amount of material.

$X$-ray diffraction and structural analysis. High-resolution room-temperature synchrotron powder diffraction data were collected at beamline 11-BM at the Advanced Photon Source, Argonne National Laboratory, Lemont, IL. A Debye-Scherrer geometry was used for the data collection. The sample was filled into a glass-capillary with an outer diameter of $0.5 \mathrm{~mm}$, which then was sealed afterwards. The obtained glass capillary was then placed into a Kapton capillary (inner diameter of $0.80 \mathrm{~mm}$ ), which was sealed using modeling clay. Diffraction patterns were obtained in the $2 \theta$ range between $0.5^{\circ}$ and $50^{\circ}$ (step size $0.001^{\circ}$ ) with a calibrated wavelength 
of $0.457841 \AA$ ( $\operatorname{Si}(111)$ double crystal monochromator). For detection, 12 independent Si(111) analyzer crystals spaced $2^{\circ}$ from each other were used in combination with $\mathrm{LaCl}_{3}$ scintillation detectors.

Rietveld-refinements were carried out using the TOPAS software package. ${ }^{37}$ The peakasymmetry was accounted for by using instrument-dependent values obtained from a standard. Rietveld-refinements were carried out in the $2 \theta$ range between $2^{\circ}$ and $35^{\circ}$ and included: (i) the scaling factor for the main phase and a 12 parameter polynomial for the background, followed by (ii) a manual reduction of the starting lattice parameters from the theoretically calculated unit cell of $\mathrm{Li}_{3} \mathrm{YI}_{6} .{ }^{20}$ (iii) The scaling factors for the $\mathrm{ErI}_{3}$ and LiI side phases. (iv) After obtaining reliable lattice parameters, the zero shift was refined. (v) The iodine atomic positions were refined, followed by the erbium position. (vi) The atomic displacement parameters, accounting for thermal motion around the equilibrium position were refined for erbium and iodine and afterwards fixed. The occupancies for erbium on both positions were constrained to result in a stoichiometric ratio for the final compound, while accounting for the different multiplicity on both sites (Wyckoff $4 d$ and $8 f$ ). Afterwards, all refined values, except for the lattice parameters and angle were refined simultaneously to obtain precise values. No lithium-related values were refined in the synchrotron-data due to the low scattering form factor of lithium. The used constraints for the refinement and results are provided in the Supporting information (Tables S1 and S2)

Neutron powder diffraction. Room-temperature neutron diffraction data were collected using the POWGEN diffractometer at the Spallation Neutron Source in Oak Ridge National Laboratory. Approximately $2 \mathrm{~g}$ of sample was loaded into a $6 \mathrm{~mm}$ diameter cylindrical vanadium sample can. Data were collected for approximately $3 \mathrm{~h}$ in the high-resolution mode using a center wavelength of $1.5 \AA$ which covers a $d$-spacing from 0.2 to $6 \AA$.

A background correction for the measured data was performed using an empty vanadium sample can measurement. A 10-parameter polynomial was used to fit the background and the peak shape was described using a convolution of a Pseudo-Voigt function and a GSAS backto-back exponential function. The refinement included: (i) scaling factors, peak shape and lattice parameters for the three phases as identified from the synchrotron diffraction data ( $\mathrm{Li}_{3} \mathrm{ErI}_{6}, \mathrm{LiI}, \mathrm{ErI}_{3}$ ). (ii) Atomic coordinates for erbium, iodine and lithium and corresponding atomic displacement parameters. Although the synchrotron data suggested a second possible site (cation exchange defect on the Li site) the refinement was performed unbiased starting from the fully ordered structure. (iii) The anti-site defect model was tested for the neutron diffraction 
data and resulted in values very comparable to the erbium occupancies on the two respective sites obtained from the synchrotron diffraction data, further supporting the existence of this native defect. (iv) A fourth lithium position is suggested to exist and exact values can be found in the SI. It needs to be mentioned, that finally opening all parameters at once was only slightly beneficial for the fit quality, but resulted in no occupancy on this fourth lithium site and also in unreasonably small atomic displacement parameters for lithium, while still keeping very similar values for the aforementioned in-plane $\mathrm{Er} / \mathrm{Li}$ anti-site disorder. The used constraints for the refinements and both structural datasets and approaches, i.e. with and without a Li4, are provided in the SI (Table S3, S4 and S5). The upcoming discussion about possible diffusion pathways will include this $\mathrm{Li} 4$ position.

Electrochemical impedance spectroscopy. Electrical conductivities were measured using AC impedance spectroscopy, using a steel press cell. The exact setup is described elsewhere. ${ }^{38}$ The powder was initially hand pressed in the press-cell, followed by a uniaxial pressing step using a pressure of $382 \mathrm{MPa}$ for 3 minutes and a subsequent slow pressure-release step. This resulted in geometrical densities of the pellets at around $90 \%$. The electrochemical impedance analysis (EIS) was conducted in the temperature range of $-40{ }^{\circ} \mathrm{C}$ to $60{ }^{\circ} \mathrm{C}$, with a temperatureequilibration time of $1 \mathrm{~h}$ per temperature step, using a VMP300 impedance analyzer (Biologic) at a frequency range of $7 \mathrm{MHz}$ to $100 \mathrm{mHz}$ with an amplitude of $10 \mathrm{mV}$.

Speed of sound measurements. Pulse-echo speed of sound measurements were performed on consolidated discs (short hand pressing with subsequent isostatic pressing at $360 \mathrm{MPa}$ for 45 min) using an Epoch 600 (Olympus) with $5 \mathrm{MHz}$ transducers for longitudinal and transverse speeds of sound. Further, knowing the average volume per lithium-ion $V$, the obtained longitudinal and transverse speeds of sound $v_{\text {long }}$ and $v_{\text {trans }}$ can be used to calculate the mean speed of sound $v_{\text {mean }}$ and Debye frequency $v_{D}$ :

$$
\begin{gathered}
v_{\text {mean }}{ }^{3}=\frac{3}{v_{\text {long }}{ }^{-3}+2 v_{\text {trans }^{-3}}} \\
v_{D}=\left(\frac{3}{4 \pi V}\right)^{1 / 3} \cdot v_{\text {mean }}
\end{gathered}
$$

A changing speed of sound corresponds to a changing Debye frequency, which are parameters that indicate changes in the lattice softness as these describe phonon vibrational frequencies of a material. For more information on the experimental setup, see reference 15. 
Bond Valence Sum (BVS) analysis. The BVS analysis was employed on the refined structure from the performed neutron diffraction analysis, in order to possibly predict preferred lithium diffusion pathways, as previously used for different lithium and sodium conduction compounds. ${ }^{9,17,32,34,39-41}$ The BVS method describes a geometric and electrostatic assessment of the lithium environment. Therefore, a bond-valence mismatch (Eq. 3) can be defined, where $V$ is the bond valence and $V_{\text {nom }}$ the nominal valence, with the diffusion pathways being represented by positions in the lattice, where this mismatch is minimal. ${ }^{42}$ The calculations were performed with empirical values for the Li-I interaction until a cutoff-distance of $7 \AA .{ }^{43}$

$$
\Delta V=\left|V-V_{\text {nom }}\right|
$$

\section{Supporting Information.}

All structural data as obtained from Rietveld refinements can be found here, as well as a comparison of the diffraction data against multiple possible space groups. Further, a crystallographic information file is available. Further details on the crystal structure investigation may be obtained from CCDC under the deposition number 1969773.

\section{AUTHOR INFORMATION}

\section{Corresponding Authors}

*wolfgang.g.zeier@pc.jlug.de;

\section{Notes}

The authors declare no competing financial interests.

\section{Acknowledgements}

The research was supported by the Deutsche Forschungsgemeinschaft (DFG) under grant number ZE 1010/4-1. The authors acknowledge the use of the Advanced Photon Source at the Argonne National Laboratory for synchrotron diffraction data, as supported by the U.S. Department of Energy, Office of Science, Office of Basic Energy Sciences, under contract no. DE-AC02-06CH11357. This research used resources at the Spallation Neutron Source a DOE Office of Science User Facility operated by the Oak Ridge National Laboratory. 


\section{References}

(1) Janek, J.; Zeier, W. G. A Solid Future for Battery Development. Nat. Energy 2016, 1, 16141.

(2) Kato, Y.; Hori, S.; Saito, T.; Suzuki, K.; Hirayama, M.; Mitsui, A.; Yonemura, M.; Iba, H.; Kanno, R. High-Power All-Solid-State Batteries Using Sulfide Superionic Conductors. Nat. Energy 2016, 1, 16030.

(3) Manthiram, A.; Yu, X.; Wang, S. Lithium Battery Chemistries Enabled by Solid-State Electrolytes. Nat. Rev. Mater. 2017, 2, 16103.

(4) Culver, S. P.; Koerver, R.; Krauskopf, T.; Zeier, W. G. Designing Ionic Conductors: The Interplay between Structural Phenomena and Interfaces in Thiophosphate-Based SolidState Batteries. Chem. Mater. 2018, 30, 4179-4192.

(5) Cussen, E. J. Structure and Ionic Conductivity in Lithium Garnets. J. Mater. Chem. 2010, $20,5167-5173$.

(6) Rettenwander, D.; Redhammer, G.; Preishuber-Pflügl, F.; Cheng, L.; Miara, L.; Wagner, R.; Welzl, A.; Suard, E.; Doeff, M. M.; Wilkening, M.; Fleig, J.; Amthauer, G. Structural and Electrochemical Consequences of $\mathrm{Al}$ and $\mathrm{Ga}$ Cosubstitution in $\mathrm{Li}_{7} \mathrm{La}_{3} \mathrm{Zr}_{2} \mathrm{O}_{12}$ Solid Electrolytes. Chem. Mater. 2016, 28, 2384-2392.

(7) Li, Y.; Han, J. T.; Wang, C. A.; Vogel, S. C.; Xie, H.; Xu, M.; Goodenough, J. B. Ionic Distribution and Conductivity in Lithium Garnet $\mathrm{Li}_{7} \mathrm{La}_{3} \mathrm{Zr}_{2} \mathrm{O}_{12}$. J. Power Sources 2012, 209, 278-281.

(8) Murugan, R.; Thangadurai, V.; Weppner, W. Fast Lithium Ion Conduction in GarnetType $\mathrm{Li}_{7} \mathrm{La}_{3} \mathrm{Zr}_{2} \mathrm{O}_{12}$. Angew. Chemie - Int. Ed. 2007, 46, 7778-7781.

(9) Weber, D. A.; Senyshyn, A.; Weldert, K. S.; Wenzel, S.; Zhang, W.; Kaiser, R.; Berendts, S.; Janek, J.; Zeier, W. G. Structural Insights and 3D Diffusion Pathways within the Lithium Superionic Conductor $\mathrm{Li}_{10} \mathrm{GeP}_{2} \mathrm{~S}_{12}$. Chem. Mater. 2016, 28, 59055915.

(10) Ong, S. P.; Mo, Y.; Richards, W. D.; Miara, L.; Lee, H. S.; Ceder, G. Phase Stability, Electrochemical Stability and Ionic Conductivity of the $\mathrm{Li}_{10 \pm 1} \mathrm{MP}_{2} \mathrm{X}_{12}(\mathrm{M}=\mathrm{Ge}, \mathrm{Si}, \mathrm{Sn}$, $\mathrm{Al}$ or $\mathrm{P}$, and $\mathrm{X}=\mathrm{O}, \mathrm{S}$ or Se) Family of Superionic Conductors. Energy Environ. Sci. 2013, 6, 148-156.

(11) Kuhn, A.; Gerbig, O.; Zhu, C.; Falkenberg, F.; Maier, J.; Lotsch, B. V. A New Ultrafast Superionic Li-Conductor: Ion Dynamics in Li 11Si2PS12 and Comparison with Other Tetragonal LGPS-Type Electrolytes. Phys. Chem. Chem. Phys. 2014, 16, 14669-14674.

(12) Kamaya, N.; Homma, K.; Yamakawa, Y.; Hirayama, M.; Kanno, R.; Yonemura, M.; 
Kamiyama, T.; Kato, Y.; Hama, S.; Kawamoto, K.; et al. A Lithium Superionic Conductor. Nat. Mater. 2011, 10, 682-686.

(13) Deiseroth, H. J.; Kong, S. T.; Eckert, H.; Vannahme, J.; Reiner, C.; Zaiß, T.; Schlosser, M. $\mathrm{Li}_{6} \mathrm{PS}_{5} \mathrm{X}$ : A Class of Crystalline Li-Rich Solids with an Unusually High $\mathrm{Li}^{+}$Mobility. Angew. Chemie - Int. Ed. 2008, 47, 755-758.

(14) Adeli, P.; Bazak, J. D.; Park, K. H.; Kochetkov, I.; Huq, A.; Goward, G. R.; Nazar, L. F. Boosting Solid-State Diffusivity and Conductivity in Lithium Superionic Argyrodites by Halide Substitution. Angew. Chemie - Int. Ed. 2019, 58, 8681-8686.

(15) Kraft, M. A.; Culver, S. P.; Calderon, M.; Böcher, F.; Krauskopf, T.; Senyshyn, A.; Dietrich, C.; Zevalkink, A.; Janek, J.; Zeier, W. G. Influence of Lattice Polarizability on the Ionic Conductivity in the Lithium Superionic Argyrodites $\mathrm{Li}_{6} \mathrm{PS}_{5} \mathrm{X}(\mathrm{X}=\mathrm{Cl}, \mathrm{Br}, \mathrm{I}) . J$. Am. Chem. Soc. 2017, 139, 10909-10918.

(16) Steiner, H.J.; Lutz, H.D. Neue schnelle Ionenleiter vom Typ $\mathrm{M}_{3} \mathrm{NCl}_{6}(\mathrm{M}=\mathrm{Li}, \mathrm{Na}, \mathrm{Ag}$; $\mathrm{N}=\mathrm{In}, \mathrm{Y})$. Z. anorg. allg. Chemie. 1992, 613, 26-30.

(17) Asano, T.; Sakai, A.; Ouchi, S.; Sakaida, M.; Miyazaki, A.; Hasegawa, S. Solid Halide Electrolytes with High Lithium-Ion Conductivity for Application in 4 V Class BulkType All-Solid-State Batteries. Adv. Mater. 2018, 30, 1803075.

(18) Li, X.; Liang, J.; Luo, J.; Banis, M. N.; Wang, C.; Li, W.; Deng, S.; Yu, C.; Zhao, F.; Hu, Y.; Sham, T. K.; Zhang, L.; Zhao, S.; Lu, S.; Huang, H.; Li, R.; Adair, K. R.; Sun, X. Air-stable $\mathrm{Li}_{3} \mathrm{InCl}_{6}$ electrolyte with high voltage compatibility for all-solid-state batteries. Environmental Science. 2019, 12, 2665-2671.

(19) Park, K. H.; Kaup, K.; Assoud, A.; Zhang, Q.; Wu, X.; Nazar, L. F. High Voltage Superionic Halide Solid Electrolytes for All-Solid-State Li-Ion Batteries. ACS Energy Lett. 2020. https://doi.org/10.1021/acsenergylett.9b02599.

(20) Xu, Z.; Chen, X.; Liu, K.; Chen, R.; Zeng, X.; Zhu, H. Influence of Anion Charge on Li Ion Diffusion in a New Solid-State Electrolyte, Li ${ }_{3} \mathrm{LaI}_{6}$. Chem. Mater. 2019, https://10.1021/acs.chemmater.9b02075

(21) Muy, S.; Voss, J.; Schlem, R.; Koerver, R.; Sedlmaier, S. J.; Maglia, F.; Lamp, P.; Zeier, W. G.; Shao-Horn, Y. High-Throughput Screening of Solid-State Li-Ion Conductors Using Lattice-Dynamics Descriptors. iScience 2019, 16, 270-282.

(22) Yamada, K.; Kumano, K.; Okuda, T. Lithium Superionic Conductors $\operatorname{Li}_{3} \operatorname{InBr}_{6}$ and LiInBr 4 Studied by 7Li, 115In NMR. Solid State Ionics 2006, 177, 1691-1695.

(23) Schlem, R.; Muy, S.; Prinz, N.; Banik, A.; Shao-Horn, Y.; Zobel, M.; Zeier, W. G. Mechanochemical Synthesis: A Tool to Tune Cation Site Disorder and Ionic Transport 
Properties of Li3MCl6 (M = Y, Er) Superionic Conductors. Adv. Energy Mater. 2019, https://doi.org/10.1002/aenm.201903719

(24) Tomita, Y.; Yonekura, H.; Yamauchi, Y.; Kobayashi, K.; Yamada, K. Substitution Effect in the Ion Conductor $\mathrm{Li}_{3} \operatorname{InBr}_{6}$, Studied by Nuclear Magnetic Resonance. Zeitschrift fur Naturforsch. - Sect. A J. Phys. Sci. 2002, 57, 447-450.

(25) Kraft, M. A.; Ohno, S.; Zinkevich, T.; Koerver, R.; Culver, S. P.; Fuchs, T.; Senyshyn, A.; Indris, S.; Morgan, B. J.; Zeier, W. G. Inducing High Ionic Conductivity in the Lithium Superionic Argyrodites $\mathrm{Li}_{6+x} \mathrm{P}_{1-\mathrm{x}} \mathrm{Ge}_{\mathrm{x}} \mathrm{S}_{5} \mathrm{I}$ for All-Solid-State Batteries. J. Am. Chem. Soc. 2018, 140, 16330-16339.

(26) Sendek, A. D.; Cheon, G.; Pasta, M.; Reed, E. J. Quantifying the Search for Solid Li-Ion Electrolyte Materials by Anion : A Data-Driven Perspective. Arxiv 2019, 1904.08996

(27) Muy, S.; Bachman, J. C.; Giordano, L.; Chang, H. H.; Abernathy, D. L.; Bansal, D.; Delaire, O.; Hori, S.; Kanno, R.; Maglia, F.; Lupart, S.; Lamp, P.; Shao-Horn, Y. Tuning Mobility and Stability of Lithium Ion Conductors Based on Lattice Dynamics. Energy Environ. Sci. 2018, 11, 850-859.

(28) Krauskopf, T.; Pompe, C.; Kraft, M. A.; Zeier, W. G. Influence of Lattice Dynamics on $\mathrm{Na}^{+}$Transport in the Solid Electrolyte $\mathrm{Na}_{3} \mathrm{PS}_{4-\mathrm{x}} \mathrm{Se}_{\mathrm{x}}$. Chem. Mater. 2017, 29, 8859-8869.

(29) Krauskopf, T.; Muy, S.; Culver, S. P.; Ohno, S.; Delaire, O.; Shao-Horn, Y.; Zeier, W. G. Comparing the Descriptors for Investigating the Influence of Lattice Dynamics on Ionic Transport Using the Superionic Conductor $\mathrm{Na}_{3} \mathrm{PS}_{4-\mathrm{x}} \mathrm{Se}_{\mathrm{x}} . J$. Am. Chem. Soc. 2018, $140,14464-14473$.

(30) Schlem, R.; Ghidiu, M.; Culver, S. P.; Hansen, A.-L.; Zeier, W. G. Changing the Static and Dynamic Lattice Effects for the Improvement of the Ionic Transport Properties within the Argyrodite $\mathrm{Li}_{6} \mathrm{PS}_{5-\mathrm{x}} \mathrm{Se}_{\mathrm{x}} \mathrm{I}$. ACS Appl. Energy Mater. 2019. https://doi.org/10.1021/acsaem.9b01794

(31) Shannon, R. D. Revised Effective Ionic Radii and Systematic Studies of Interatomie Distances in Halides and Chaleogenides. Acta Crystallogr. 1976, A32, 751.

(32) Wang, S.; Bai, Q.; Nolan, A. M.; Liu, Y.; Gong, S.; Sun, Q.; Mo, Y. Lithium Chlorides and Bromides as Promising Solid-State Chemistries for Fast Ion Conductors with Good Electrochemical Stability. Angew. Chemie - Int. Ed. 2019, 58, 8039-8043.

(33) Lee, J.; Urban, A.; Li, X.; Su, D.; Hautier, G.; Ceder, G. Unlocking the Potential of Cation-Disordered Oxides for Rechargeable Lithium Batteries. Science, 2014, 343, 519522.

(34) Prasada Rao, R.; Chen, H.; Adams, S. Stable Lithium Ion Conducting Thiophosphate 
Solid Electrolytes $\mathrm{Li}_{\mathrm{x}}\left(\mathrm{PS}_{4}\right) \mathrm{YXz}(\mathrm{X}=\mathrm{Cl}, \mathrm{Br}, \mathrm{I})$. Chem. Mater. 2019, 31, 8649-8662.

(35) Brug, G. J.; van den Eeden, A. L. G.; Sluyters-Rehbach, M.; Sluyters, J. H. The Analysis of Electrode Impedances Complicated by the Presence of a Constant Phase Element. $J$. Electroanal. Chem. 1984, 176, 275-295.

(36) West, A.; Irvine, J.; Sinclair, D. Electroceramics : Characterization by Impedance Spectroscopy. Adv. Mater. 1990, 2, 132-138.

(37) Coelho, A. A. TOPAS and TOPAS-Academic: An Optimization Program Integrating Computer Algebra and Crystallographic Objects Written in C++: An. J. Appl. Crystallogr. 2018, 51, 210-218.

(38) Zhang, W.; A. Weber, D.; Weigand, H.; Arlt, T.; Manke, I.; Schröder, D.; Koerver, R.; Leichtweiss, T.; Hartmann, P.; G. Zeier, W.; Janek, J.; Interfacial Processes and Influence of Composite Cathode Microstructure Controlling the Performance of AllSolid-State Lithium Batteries. ACS Appl. Mater. \& Interfaces 2017, 9, 17835-17845.

(39) Schlem, R.; Till, P.; Weiss, M.; Krauskopf, T.; Culver, S. P.; Zeier, W. G. Ionic Conductivity of the NASICON-Related Thiophosphate $\mathrm{Na}_{1+\mathrm{x}} \mathrm{Ti}_{2-\mathrm{x}} \mathrm{Ga}_{\mathrm{x}}\left(\mathrm{PS}_{4}\right)_{3}$. Chem. - A Eur. J. 2019, 25, 4143-4148.

(40) Rayavarapu, P. R.; Sharma, N.; Peterson, V. K.; Adams, S. Variation in Structure and Li ${ }^{+}$-Ion Migration in Argyrodite-Type $\mathrm{Li}_{6} \mathrm{PS}_{5} \mathrm{X}(\mathrm{X}=\mathrm{Cl}, \mathrm{Br}, \mathrm{I})$ Solid Electrolytes. J. Solid State Electrochem. 2012, 16, 1807-1813.

(41) Rao, R. P.; Adams, S. Studies of Lithium Argyrodite Solid Electrolytes for All-SolidState Batteries. Physica Status Solidi (A) Applications and Materials Science. 2011, 1804-1807.

(42) Adams, S. Bond Valence Analysis of Structure-Property Relationships in Solid Electrolytes. J. Power Sources 2006, 159, 200-204.

(43) Adams, S. Relationship between Bond Valence and Bond Softness of Alkali Halides and Chalcogenides. Acta Crystallogr. Sect. B Struct. Sci. 2001, 57, 278-287. 


\title{
Supporting Information-
}

\section{A lattice dynamical approach for finding the lithium superionic conductor $\mathrm{Li}_{3} \mathrm{ErI}_{6}$}

\author{
Roman Schlem ${ }^{\mathrm{a}, \mathrm{b}}$, Tim Bernges ${ }^{\mathrm{a}, \mathrm{b}}$, Cheng Li $^{\mathrm{c}}$, Marvin A. Kraft ${ }^{\mathrm{a}, \mathrm{b}}$, Nicolo Minafra ${ }^{\mathrm{a}, \mathrm{b}}$, \\ Wolfgang G. Zeier*a,b \\ ${ }^{a}$ Institute of Physical Chemistry, Justus-Liebig-University Giessen, Heinrich-Buff-Ring 17, D- \\ 35392 Giessen, Germany. \\ ${ }^{b}$ Center for Materials Research (LaMa), Justus-Liebig-University Giessen, Heinrich-Buff-Ring 16, \\ D-35392 Giessen, Germany.
}

' Jülich Centre for Neutron Science (JCNS), Forschungszentrum Jülich GmbH, Outstation at SNS, 1 Bethel Valley Road, Oak Ridge, Tennessee 37831-6473, United States 


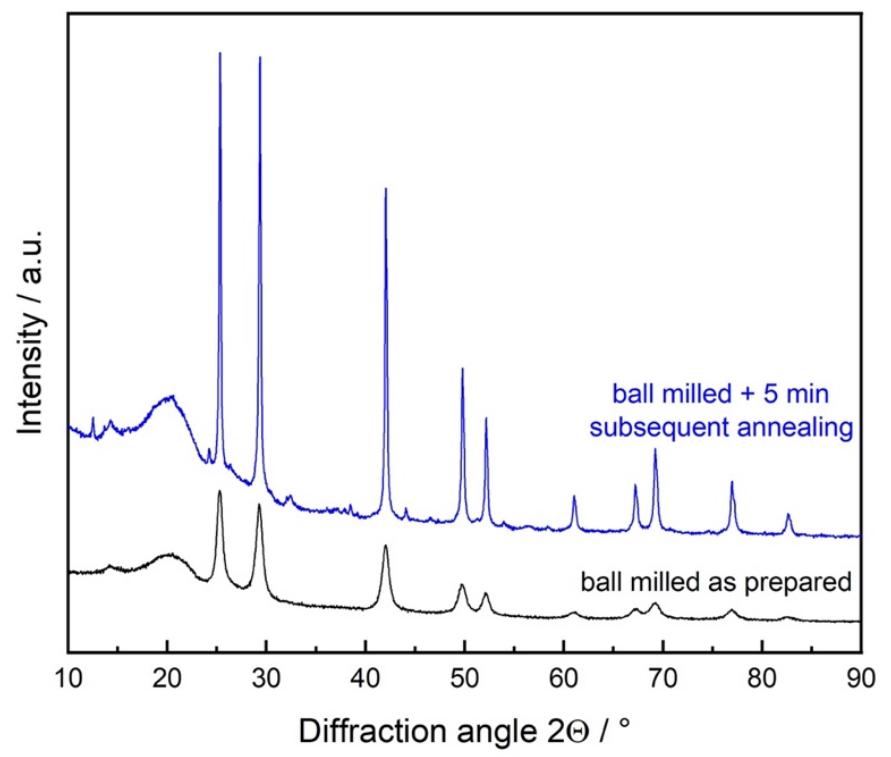

Figure S1: Comparison between the $\mathrm{Li}_{3} \mathrm{ErI}_{6}$ sample right after ball milling and after an additional $5 \mathrm{~min}$ annealing step. The reduction of the background and sharper reflections support the expected increase in crystallinity. This crystallized sample was used for the synchrotron diffraction data collection. 

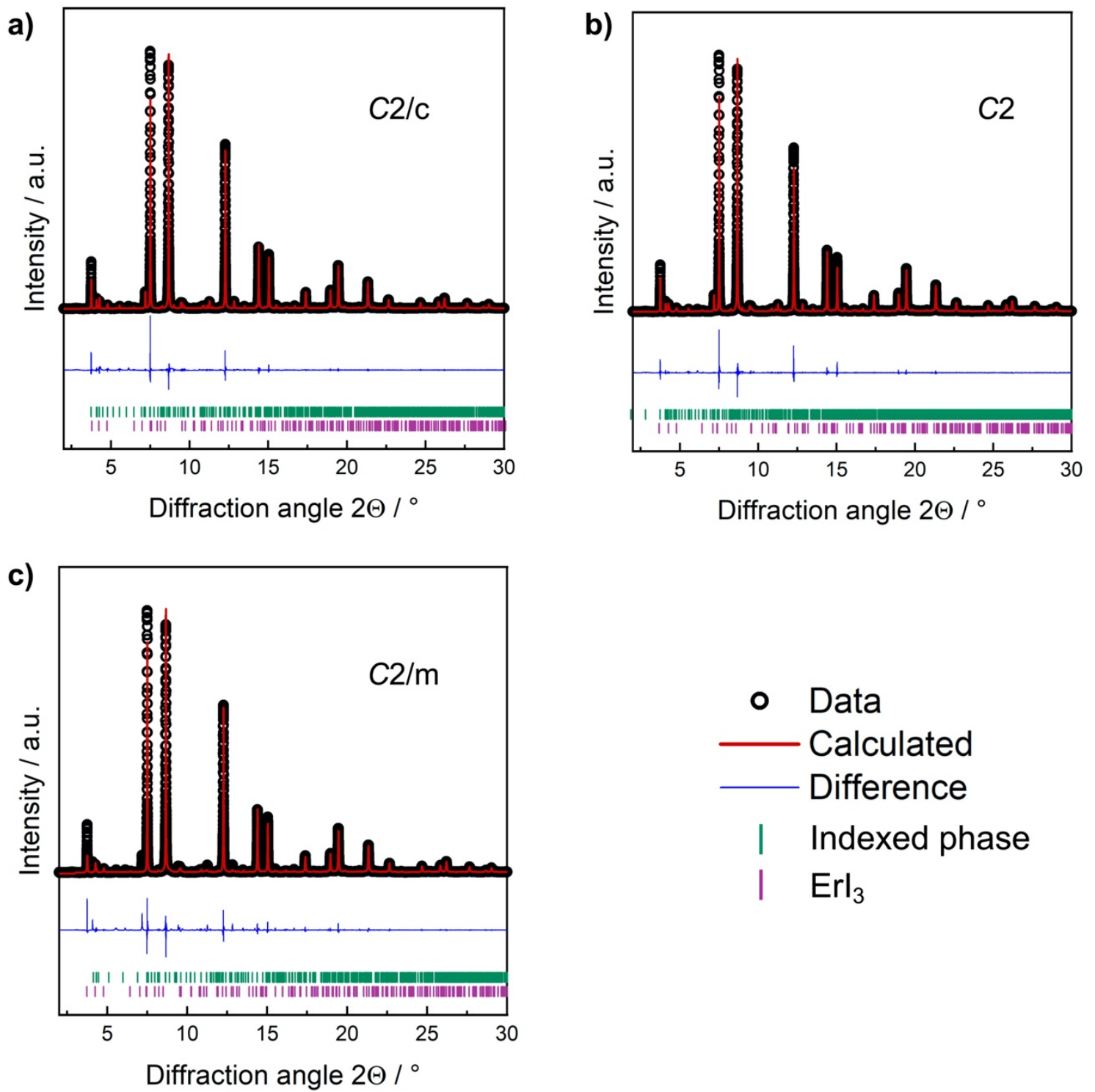

Figure S2: Comparison of Pawley-fits against the collected synchrotron X-ray diffraction data using the different possible space groups. Here, only the space groups $C 2 / c$ and $C 2$ match all the observed reflection positions, further suggesting one of these being the correct space groups. 
Table S1: Used constraints for the synchrotron X-ray diffraction data.

\begin{tabular}{|c|c|c|c|c|c|c|}
\hline \multirow{2}{*}{ Atom } & \multirow{2}{*}{$\begin{array}{l}\text { Wyckoff } \\
\text { position }\end{array}$} & \multicolumn{3}{|c|}{ Atomic coordinates } & \multirow{2}{*}{$O c c}$. & \multirow{2}{*}{$B_{i s o} / \AA^{2}$} \\
\hline & & $x$ & $y$ & $z$ & & \\
\hline Er1 & $4 d$ & 0.25 & 0.25 & 0.5 & $1-2 \cdot o c c 1$ & Varl \\
\hline Er2 & $8 f$ & 0.25 & pos 1 & 1 & $o c c 1$ & Varl \\
\hline I1 & $8 f$ & pos2 & pos 1 & pos7 & 1 & Var2 \\
\hline I2 & $8 f$ & pos3 & pos5 & pos8 & 1 & Var2 \\
\hline I3 & $8 f$ & pos4 & pos6 & pos9 & 1 & Var2 \\
\hline
\end{tabular}

Table S2: Rietveld-Refinement results against synchrotron diffraction data, using space group $C 2 / c$.

\section{$\mathrm{Li}_{3} \mathrm{ErI}_{6}$ synchrotron diffraction data}

Lattice parameter: $a=7.4215(2) b=12.8509(2), c=14.2130(3), \beta=99.98(2)^{\circ}$

$R_{\mathrm{WP}}=12.1 \%, R_{\exp }=3.6 \%$, Goodness of fit: 3.4

Impurity phase: $4 \mathrm{wt} \%$ total of $\mathrm{LiI}$ and $\mathrm{ErI}_{3}$

\begin{tabular}{ccccccc}
\multirow{2}{*}{ Atom } & $\begin{array}{c}\text { Wyckoff } \\
\text { position }\end{array}$ & \multicolumn{3}{c}{ Atomic coordinates } & \multirow{2}{*}{ Occ. } & \multirow{2}{*}{$\boldsymbol{B}_{\text {iso }} / \AA^{\mathbf{2}}$} \\
\cline { 3 - 5 } Er1 & $4 d$ & 0.25 & 0.25 & 0.5 & $0.6919(8)$ & $2.05(3)$ \\
\hline Er2 & $8 f$ & 0.25 & $0.4173(4)$ & 1 & $0.1540(8)$ & $2.05(3)$ \\
\hline $\mathbf{I} 1$ & $8 f$ & $0.1245(5)$ & $0.4173(4)$ & $0.6257(3)$ & 1 & $1.92(1)$ \\
\hline $\mathbf{I 2}$ & $8 f$ & $0.1171(3)$ & $0.2490(4)$ & $0.1222(1)$ & 1 & $1.92(1)$ \\
\hline $\mathbf{I 3}$ & $8 f$ & $0.1135(5)$ & $0.0904(2)$ & $0.6209(3)$ & 1 & $1.92(1)$ \\
\hline
\end{tabular}

Table S3: Used constraints for neutron diffraction data.

\begin{tabular}{|c|c|c|c|c|c|c|}
\hline \multirow{2}{*}{ Atom } & \multirow{2}{*}{$\begin{array}{l}\text { Wyckoff } \\
\text { position }\end{array}$} & \multicolumn{3}{|c|}{ Atomic coordinates } & \multirow{2}{*}{$O c c}$. & \multirow{2}{*}{$B_{i s o} / \AA^{2}$} \\
\hline & & $x$ & $y$ & $z$ & & \\
\hline Er1 & $4 d$ & 0.25 & 0.25 & 0.5 & $1-2 \cdot(1-o c c 1)$ & Varl \\
\hline Li1 & $4 d$ & 0.25 & 0.25 & 0.5 & $1-(1-2 \cdot(1-o c c 1))$ & Varl \\
\hline Er2 & $8 f$ & 0.25 & pos1 & 1 & $1-o c c 1$ & Varl \\
\hline Li2 & $8 f$ & 0.25 & pos1 & 1 & $o c c 1$ & Varl \\
\hline I1 & $8 f$ & pos2 & pos1 & pos7 & 1 & Var2 \\
\hline 12 & $8 f$ & pos3 & pos5 & pos8 & 1 & Var2 \\
\hline $\mathbf{I 3}$ & $8 f$ & pos 4 & pos6 & pos 9 & 1 & Var2 \\
\hline Li3 & $4 e$ & 0 & pos1 & 0.25 & $o c c 2$ & Var3 \\
\hline Li4 & $4 e$ & 0 & pos10 & 0.25 & $1-o c c 2$ & Var3 \\
\hline
\end{tabular}


Table S4: Rietveld-Refinement results against neutron diffraction data, using space group C2/c.

\begin{tabular}{|c|c|c|c|c|c|c|}
\hline \multicolumn{7}{|c|}{$\mathrm{Li}_{3} \mathrm{ErI}_{6}$ neutron diffraction data } \\
\hline \multicolumn{7}{|c|}{ Lattice parameter: $a=7.413(4) b=11.838(6), c=14.200(7), \beta=100.01(5)^{\circ}$} \\
\hline \multicolumn{7}{|c|}{$R \mathrm{wP}=1.6 \%, R_{\exp }=1.1 \%$, Goodness of fit: 1.4} \\
\hline \multicolumn{7}{|c|}{ Impurity phase: $5 \mathrm{wt} \%$ total of LiI and $\mathrm{ErI}_{3}$} \\
\hline \multirow{2}{*}{ Atom } & \multirow{2}{*}{$\begin{array}{l}\text { Wyckoff } \\
\text { position }\end{array}$} & \multicolumn{3}{|c|}{ Atomic coordinates } & \multirow{2}{*}{ Occ. } & \multirow{2}{*}{$B_{i s o} / \AA^{2}$} \\
\hline & & $x$ & $y$ & $z$ & & \\
\hline Er1 & $4 d$ & 0.25 & 0.25 & 0.5 & $0.68(2)$ & $3.4(1)$ \\
\hline Li1 & $4 d$ & 0.25 & 0.25 & 0.5 & $0.32(2)$ & $3.4(1)$ \\
\hline Er2 & $8 f$ & 0.25 & $0.4218(8)$ & 1 & $0.16(2)$ & $3.4(1)$ \\
\hline Li2 & $8 f$ & 0.25 & $0.4218(8)$ & 1 & $0.84(2)$ & $3.4(1)$ \\
\hline I1 & $8 f$ & $0.116(3)$ & $0.4218(8)$ & $0.628(1)$ & 1 & $1.15(2)$ \\
\hline 12 & $8 f$ & $0.112(1)$ & $0.242(2)$ & $0.1211(8)$ & 1 & $1.15(2)$ \\
\hline $\mathbf{I 3}$ & $8 f$ & $0.111(3)$ & $0.0920(1)$ & $0.617(1)$ & 1 & $1.15(2)$ \\
\hline Li3 & $4 e$ & 0 & $0.4218(8)$ & 0.25 & $0.2(1)$ & $5(1)$ \\
\hline Li4 & $4 e$ & 0 & $0.725(6)$ & 0.25 & $0.8(1)$ & $5(1)$ \\
\hline
\end{tabular}

Table S5: Rietveld-Refinement results against neutron diffraction data without the $4^{\text {th }}$ lithium position, using space group $C 2 / c$.

\begin{tabular}{|c|c|c|c|c|c|c|}
\hline $\begin{array}{l}\mathrm{Li}_{3} \mathrm{Erl} \\
\text { Lattice }\end{array}$ & \multicolumn{5}{|c|}{ Lattice parameter: $a=7.411(4) b=11.843(8), c=14.201(8), \beta=100.01(7)^{\circ}$} & \\
\hline \multicolumn{7}{|c|}{$R_{\mathrm{WP}}=1.5 \%, R_{\mathrm{exp}}=1.1 \%$, Goodness of fit: 1.4} \\
\hline \multicolumn{7}{|c|}{ Impurity phase: $5 \mathrm{wt} \%$ total of LiI and $\mathrm{ErI}_{3}$} \\
\hline \multirow{2}{*}{ Atom } & \multirow{2}{*}{$\begin{array}{l}\text { Wyckoff } \\
\text { position }\end{array}$} & \multicolumn{3}{|c|}{ Atomic coordinates } & \multirow{2}{*}{ Occ. } & \multirow{2}{*}{ Biso / $\AA^{2}$} \\
\hline & & $x$ & $y$ & $z$ & & \\
\hline Er1 & $4 d$ & 0.25 & 0.25 & 0.5 & $0.57(3)$ & $0.3(3)$ \\
\hline Li1 & $4 d$ & 0.25 & 0.25 & 0.5 & $0.43(3)$ & $0.3(3)$ \\
\hline Er2 & $8 f$ & 0.25 & $0.4218(8)$ & 1 & $0.22(1)$ & $0.3(3)$ \\
\hline Li2 & $8 f$ & 0.25 & $0.4218(8)$ & 1 & $0.78(1)$ & $0.3(3)$ \\
\hline I1 & $8 f$ & $0.117(3)$ & $0.4218(8)$ & $0.628(1)$ & 1 & $1.23(5)$ \\
\hline $\mathbf{I 2}$ & $8 f$ & $0.118(2)$ & $0.2418(2)$ & $0.123(8)$ & 1 & $1.23(5)$ \\
\hline $\mathbf{I 3}$ & $8 f$ & $0.106(2)$ & $0.087(2)$ & $0.619(1)$ & 1 & $1.23(5)$ \\
\hline Li3 & $4 e$ & 0 & $0.4218(8)$ & 0.25 & 1 & $1.0(7)$ \\
\hline
\end{tabular}


